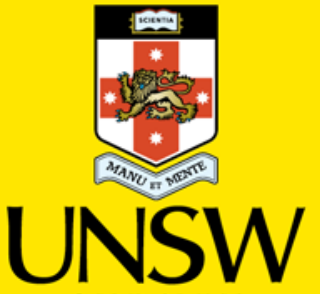

S Y D N Y Y
Australia's

Global

University
Business School / School of Economics

\section{UNSW Business School Working Paper}

UNSW Business School Research Paper No. 2017 ECON 11

Learning to Believe in Secular Stagnation

Christopher G. Gibbs 


\title{
Learning to Believe in Secular Stagnation
}

\author{
Christopher G. Gibbs* \\ UNSW Australia
}

February 2017

\begin{abstract}
This paper shows that a secular stagnation equilibrium as proposed by Eggertsson and Mehrotra (2014) is E-stable. This is in contrast to the often studied liquidity trap equilibrium that exists in representative agent New Keynesian models at the zero lower bound when there is active monetary policy following a Taylor rule. This result reconciles the observed stable low growth and low inflation outcomes since the end of the Global Financial Crisis with the instability predicted by the New Keynesian model using a standard modeling framework. The stability of the secular stagnation equilibrium is due to the assumption of downwardly rigid nominal wages and overlapping generations. At the zero lower bound, the wage friction determines the price level and makes inflation a predetermined variable, while overlapping generations weakens the negative relationship between expected output and the real interest rate.
\end{abstract}

JEL Classifications: E31; E32; E52; D83; D84

Key Words: Secular stagnation; Expectations; Adaptive learning; Zero lower bound.

\section{Introduction}

A disconnect exists between the predictions of the standard representative agent New Keynesian (NK) model and the low inflation, low growth outcomes observed in much of the developed world since the end of the Global Financial Crisis. Although Benhabib et al. (2001) (BSGU) showed that such outcomes are predicted by one equilibrium of the NK model with active monetary policy at the zero lower bound (ZLB), that equilibrium is both indeterminate and E-unstable (Evans and Honkapohja (2005); Eusepi (2007); Evans et al. (2008); Benhabib et al. (2014)). Indeterminacy and E-instability both predict that

*Gibbs: UNSW Business School, UNSW Sydney, NSW 2052. e-mail: christopher.gibbs@unsw.edu.au. I would like to thank George Evans, Neil Mehrotra, Bruce Preston, and Lauren Gibbs for discussions on this paper. All errors are my own. 
Table 1: US Real GDP Growth and PCE Inflation Comparisons

\begin{tabular}{lccccccc}
\hline \multirow{2}{*}{ Sample } & \multicolumn{4}{c}{$\begin{array}{c}c \\
\text { Neal GDP }\end{array}$} & \multicolumn{2}{c}{ Inflation } \\
\hline 2009q3 - 2015q4 & 26 & 2.13 & 2.61 & & 1.51 & 1.20 & \\
$1984 q 1-2007 q 3$ & 94 & 3.14 & 3.94 & -1.33 & 2.50 & 1.50 & -0.30 \\
Excluding Recessions & & & & & & & \\
\hline 1984q1 - 2007q3 & 88 & 3.39 & 2.98 & -0.37 & 2.51 & 1.32 & -0.12 \\
\hline
\end{tabular}

Notes: This table compares the variances of quarterly real GDP growth and PCE Inflation expressed as annual rates for the ZLB period following the Global Financial Crisis to those observed during the Great Moderation. Levene's tests of the null hypothesis of equal variances fail to reject at standard confidence levels.

volatility should increase at the ZLB. However, during the ZLB period in the US following the end of the recession, the variance of output and inflation are statistically no different and qualitatively less than during the Great Moderation as shown in Table 1. This disconnect has fractured the debate on the relevance of this steady state for describing recent economic performance with papers such as Christiano et al. (2016) downplaying its importance, while Bullard (2010) and Evans et al. (2016) continue to warn that it is relevant.

Eggertsson and Mehrotra (2014) put forward an overlapping generations model to characterize the low inflation, low growth outcomes as a secular stagnation equilibrium consistent with the stylized facts proposed by Summers (2014). The secular stagnation equilibrium is generated through multiplicity in the equilibrium real interest rate due to intergenerational lending. Eggertsson and Mehrotra's model can generate three steady states: the usual targeted steady state, the liquidity trap of BSGU, and a third secular stagnation steady state.

In this paper, I show that the Rational Expectations Equilibria (REE) associated with the target steady state and the secular stagnation steady state are E-stable, while the BGSU REE remains unstable. The stability arises due to the assumption of downwardly rigid nominal wages and the overlapping generations structure of the model. The downward rigidity in wages determines the price level in the secular stagnation equilibrium making it a function of past prices and output and independent of inflation expectations. The overlapping generations structure weakens the negative relationship between expected output and the real interest rate, which further stabilizes expectations. The results reconcile BGSU with observed stable low growth and low inflation outcomes and illustrate that asymmetric nominal rigidity and overlapping generations can play a stabilizing role for expectations at the ZLB. 
The remainder of the paper proceeds as follows. Section 2 introduces the model and describes the three steady states. Section 3 studies the E-stability properties of the equilibria. Section 4 discusses the results. Section 5 concludes.

\section{The Model}

The basic model of Eggertsson and Mehrotra is a three period overlapping generations model with an exogenously imposed debt constraint. A representative household in each generation maximizes the following utility function

$$
\max _{C_{t}^{y}, C_{t+1}^{m}, C_{t+2}^{o}} \mathbb{E}_{t}\left[\ln \left(C_{t}^{y}\right)+\beta \ln \left(C_{t+1}^{m}\right)+\beta^{2} \ln \left(C_{t+2}^{o}\right)\right]
$$

subject to

$$
\begin{aligned}
P_{t} C_{t}^{y} & =B_{t}^{y} \\
P_{t+1} C_{t+1}^{m} & =P_{t+1} Y_{t+1}^{m}-\left(1+i_{t}\right) B_{t}^{y}+B_{t+1}^{m} \\
P_{t+2} C_{t+2}^{0} & =\left(1+i_{t+1}\right) B_{t+1}^{m} \\
\left(1+r_{t}\right) B_{t}^{i} & \leq P_{t} D_{t},
\end{aligned}
$$

where the $y$ stands for young, $m$ stands for middle, $o$ stands for old, $B_{t}^{i}$ for $i=y, m, o$ is a one period risk free nominal bond, $r_{t}$ is the real interest rate, and $D_{t}$ is the exogenous debt constraint. ${ }^{1}$ The young do not work and are assumed to borrow the maximum amount allowed. The middle generation is employed and earns wages, repays debt, and saves for retirement giving rise to the following Euler equation

$$
\frac{1}{C_{t}^{m}}=\beta \mathbb{E}_{t} \frac{1}{C_{t+1}^{o}}\left(1+i_{t}\right) \frac{P_{t}}{P_{t+1}} .
$$

The old generation consumes their savings plus interest.

The real interest rate in the economy is determined by the supply and demand for loans. Loans are provided by the middle generation such that

$$
\operatorname{Loan}_{t}^{s}=\frac{\beta}{1+\beta}\left(Y_{t}^{m}-D_{t-1}\right)
$$

\footnotetext{
${ }^{1}$ This setup also implicitly assumes that the government issues a nominal bond whose rate of return $i_{t}$ is controlled by the central bank. The government bonds, however, are assumed to trade in zero net supply making only private debt matter in equilibrium. Eggertsson and Mehrotra (2014) also consider a case with explicit fiscal policy. The results presented in this paper are the same in that case.
} 
The young generation is assumed to borrow $D_{t} /\left(1+r_{t}\right)$, which implies that demand for loans is

$$
\operatorname{Loan}_{t}^{d}=\frac{1+g_{t}}{1+r_{t}} D_{t}
$$

where $g_{t}$ is the population growth rate. Equating loan demand and supply determines the real interest rate:

$$
1+r_{t}=\frac{1+\beta}{\beta} \frac{\left(1+g_{t}\right) D_{t}}{Y_{t}^{m}-D_{t-1}}
$$

The nominal interest rate is set by the central bank following a standard Taylor rule

$$
\left(1+i_{t}\right)=\max \left\{1,\left(1+i^{*}\right)\left(\frac{\Pi_{t}}{\bar{\Pi}}\right)^{\phi_{\pi}}\right\}
$$

The production side of the economy is assumed to be perfectly competitive with households supplying labor perfectly inelastically. Production is given by

$$
y_{t}=L_{t}^{\alpha}
$$

and nominal wages are assumed to be downwardly rigid

$$
\frac{\tilde{W}_{t}}{P_{t}}=\alpha L_{t}^{\alpha-1}
$$

where

$$
\tilde{W}_{t}=\max \left\{\gamma W_{t-1}+(1-\gamma) P_{t} \alpha \bar{L}^{\alpha-1}, P_{t} \alpha \bar{L}^{\alpha-1}\right\}
$$

and $\bar{L}$ is normalized to 1 . The model for certain parameterizations has three steady states. Figure 1 illustrates the case with two full employment equilibria that roughly correspond to the ones described by BSGU and the secular stagnation equilibrium. ${ }^{2}$

\footnotetext{
${ }^{2}$ The steady state relationships for inflation and output are given by

$$
Y^{A S}=\left\{\begin{array}{cl}
0 & \text { if } \Pi>1 \\
\left(\frac{1-\gamma \Pi^{-1}}{1-\gamma}\right)^{\frac{\alpha}{1-\alpha}} & \text { if } \Pi<1
\end{array}, Y^{A D}=\left\{\begin{array}{cl}
D+\frac{1+\beta}{\beta}(1+g) D \frac{\bar{\Pi}^{\phi_{\pi}}}{1+i^{*}} \frac{1}{\Pi^{\phi_{\pi}-1}} & \text { if } i>0 \\
D+\frac{1+\beta}{\beta}(1+g) D \Pi & \text { if } i=0
\end{array}\right.\right.
$$
}


Figure 1: Steady States

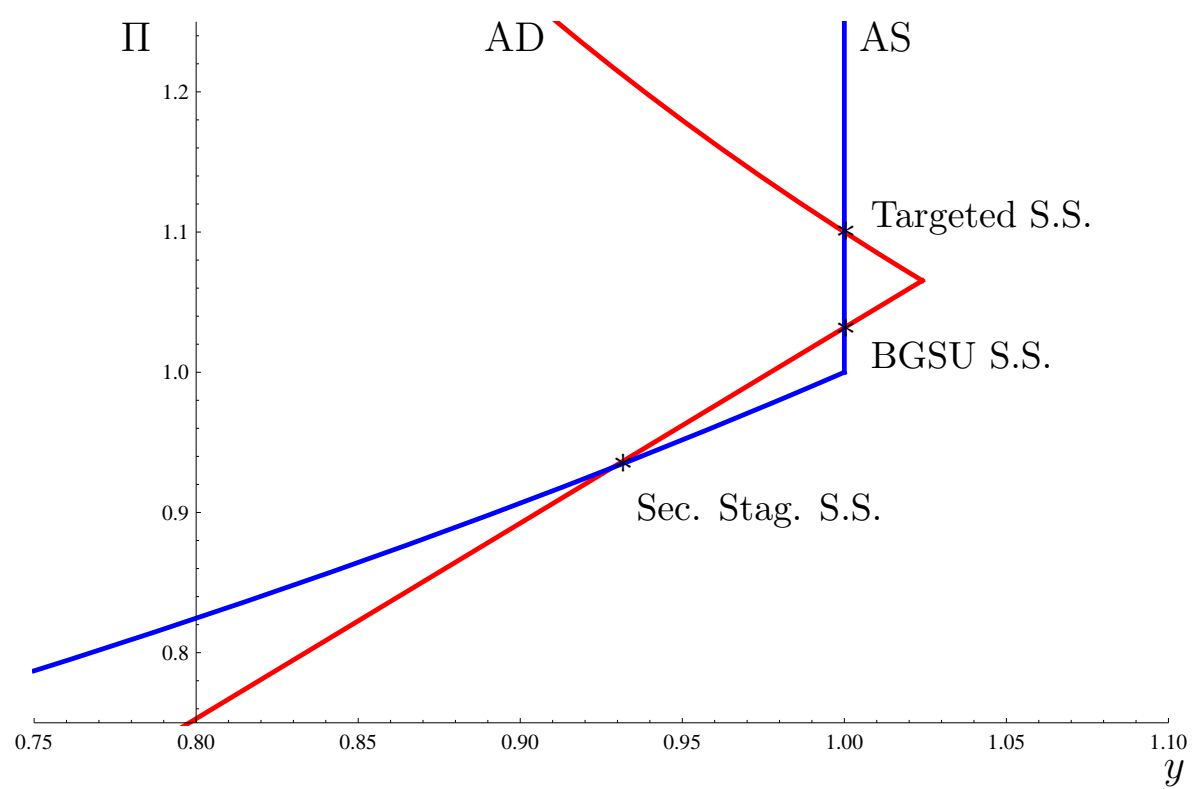

Notes: The model calibration is $\beta=0.77, D=0.26, g=0.2, \Pi^{*}=1.1, \phi_{\pi}=2, \gamma=0.3$, and $\alpha=0.7$.

\section{$3 \quad$ E-stability}

To study E-stability, I log-linearize the model around each of the three steady states and posit that agents' perceived law of motion (PLM) for the economy is consistent with the functional form of the minimum state variable rational expectations (MSV-RE) solution. Starting with the target steady state, local dynamics are described by the following equation

$$
\pi_{t}=\frac{1}{\phi_{\pi}}\left(\mathbb{E}_{t} \pi_{t+1}+d_{t}+g_{t}+\mu d_{t-1}\right)
$$

where $\mu=D /\left(Y_{s s}-D\right)$, and $d_{t}$ and $g_{t}$ are assumed to follow mean zero AR(1) processes. ${ }^{3}$ The MSV-RE solution in this case is given by

$$
\pi_{t}=\bar{a}+\bar{b} d_{t-1}+\bar{c} g_{t}+e_{t}
$$

where $\bar{a}=0, \bar{b}=\left(\phi_{\pi}-\rho_{d}\right)^{-1}\left(\mu+\rho_{d}\right), \bar{c}=\left(\phi_{\pi}-\rho_{d}\right)^{-1}$, and $e_{t}=(\bar{b}+1) \epsilon_{t}$ such that $\epsilon_{t}$ is white noise.

Proposition 1: The targeted equilibrium is E-stable if $\phi_{\pi}>1$.

\footnotetext{
${ }^{3}$ I assume $d_{t}=\rho_{d} d_{t-1}+\epsilon_{d, t}$ and $g_{t}=\rho_{g} g_{t-1}+\epsilon_{g, t}$ such that $-1<\rho_{d}<1$ and $-1<\rho_{g}<1$. Also, as is common in the literature, I assume agents know $\rho_{d}$ and $\rho_{g}$.
} 
The details of all propositions are given in the appendix. The E-stability condition in this case is the familiar Taylor-principle that interest rates must respond more than one-for-one to changes in inflation.

Next, I log-linearize around the BSGU liquidity trap steady state. The log-linearized aggregate demand curve is given by

$$
\xi y_{t}=\mathbb{E}_{t} \pi_{t+1}+d_{t}+\mu d_{t-1}+g_{t},
$$

where $\xi=Y_{s s} /\left(Y_{s s}-D\right)$. Aggregate supply in this case is $y_{t}=0$ for all $t$, which combined with (16) and using recursive substitution yields

$$
\pi_{t}=\frac{1}{\mu}\left(\mathbb{E}_{t} \pi_{t+1}+d_{t}+g_{t}\right)-\mu d_{t-2}-g_{t-1}
$$

The MSV-RE in this case is

$$
\pi_{t}=\bar{a}+\bar{b} d_{t-2}+\bar{c} g_{t-1}+\bar{f} \epsilon_{d, t-1}
$$

where $\bar{a}=0, \bar{b}=-\left(\mu+\rho_{d}\right), \bar{c}=-1$, and $\bar{f}=-1$.

Proposition 2: The BGSU liquidity trap equilibrium is E-stable if

$$
\frac{Y_{s s}-D}{D}<1
$$

The liquidity trap is E-unstable if the debt limit is less than one-half of steady state income. This restriction effectively rules out E-stability of this equilibrium for plausible calibrations of the model because increases in $D$ shift the $\mathrm{AD}$ curve shown in Figure 1 to the right. Large values of $D$ can eliminate both the BGSU and the secular stagnation equilibria.

Finally, for the secular stagnation equilibrium, I log-linearize around the upward sloping aggregate supply curve

$$
\pi_{t}=\frac{\Pi_{s s}}{\gamma} \frac{1-\alpha}{\alpha}\left(y_{t}-\frac{\gamma}{\Pi_{s s}} y_{t-1}\right)
$$

and substitute it into Equation (16) to get

$$
y_{t}=m_{0} \mathbb{E}_{t} y_{t+1}+m_{1}\left(d_{t}+g_{t}\right)+m_{2} d_{t-1}
$$


where

$$
m_{0}=\frac{\Pi_{s s}(1-\alpha)}{\gamma(1+\alpha(\xi-1))}
$$

$m_{1}=\alpha(1+\alpha(\xi-1))^{-1}$, and $m_{2}=\mu \alpha(1+\alpha(\xi-1))^{-1}$. The MSV-RE solution is given by

$$
y_{t}=\bar{a}+\bar{b} d_{t-1}+\bar{c} g_{t}+\epsilon_{t}
$$

where $\bar{a}=0, \bar{b}=\left(m_{1} \rho_{d}+m_{2}\right)\left(1-m_{0} \rho_{d}\right)^{-1}$, and $\bar{c}=m_{1}\left(1-m_{0} \rho_{g}\right)^{-1}$.

Proposition 3: If the secular stagnation equilibrium exists, then it is E-stable.

The intuition for this result is that $m_{0}$ is determined by the relative slopes of the aggregate supply and aggregate demand curves in the neighborhood of the secular stagnation steady state. If the slopes are such that the steady state exists, as shown in Figure 1, then it follows that $m_{0}<1$, which is the necessary condition for E-stability in this case. Therefore, when the secular stagnation equilibrium exists, it is also E-stable. ${ }^{4}$

\section{Discussion}

There are two reasons the secular stagnation equilibrium is E-stable while the liquidity trap equilibrium is not. First, the assumption of downwardly rigid nominal wages determines the price level and makes inflation a predetermined variable. The price level in the basic NK model and in the model discussed here is determined by monetary policy when not at the ZLB. ${ }^{5}$ At the ZLB, monetary policy is no longer active and the price level becomes indeterminate. However, when inflation is negative $(\Pi<1)$ the downward wage rigidity kicks in and determines the price level as a function past prices and aggregate demand. To see this, take Equation (12) and (13) and recursively substitute backwards

$$
(1-\gamma) \alpha \bar{L}^{\alpha-1} P_{t}+\gamma^{T} W_{t-T}+(1-\gamma) \sum_{j=1}^{T-1} \gamma^{J} \alpha \bar{L}^{\alpha-1} P_{t-j}=\alpha L_{t}^{\alpha-1} P_{t}
$$

\footnotetext{
${ }^{4}$ Eggertsson and Mehrotra (2014) show that the same argument also implies determinacy of the equilibrium.

${ }^{5}$ Assuming fiscal policy is passive. See for example Leeper and Leith (2016) for a discussion on the role of fiscal policy in determining the price level.
} 
where $T$ is the last period before the downward rigidity first comes into effect. Then let $\bar{L}=1, L_{t}=y_{t}^{1 / \alpha}$, and rearrange to get

$$
P_{t}=\frac{\gamma^{T} \alpha P_{t-T}+(1-\gamma) \sum_{j=1}^{T-1} \gamma^{J} \alpha P_{t-j}}{\alpha y_{t}^{\frac{\alpha-1}{\alpha}}-(1-\gamma) \alpha}
$$

The intuition for this mechanism is that prices are constrained by the nominal wages a firm must pay. Through the wage rigidity, the dynamics of the model only depend on expectations of output. ${ }^{6}$

This assumption alone is not sufficient to generate expectational stability in most cases. For example, Schmitt-Grohé and Uribe (2016) considers precisely this type of wage rigidity to construct an equilibrium at the ZLB in a representative agent NK model, which is only E-stable for very extreme wage rigidity. This result is discussed in detail in Appendix B.

The other assumption that contributes to expectational stability at the ZLB is the overlapping generations structure. In this environment, expectations of future inflation i.e. real interest rates at the ZLB - have a smaller effect on current and expected output than in the representative agent framework. This is because current aggregate demand is constrained by past decisions because the middle generation's debt burden is based on last period's interest rate. ${ }^{7}$ Therefore, beliefs about future inflation and output have less feedback here than in the infinitely lived representative agent case, which helps to stabilize beliefs in the absence of active monetary policy.

In other related work, Evans et al. (2016) impose exogenous lower bounds on inflation and consumption in a representative agent NK model with adaptive learning. They show that this assumption also creates a third steady state that is E-stable. It appears that similar mechanisms are at play in their specification. The introduction of a downward rigidity - a floor in their case - determines the price level and breaks the relationship between expectations of future output and the real interest rate since the inflation floor is also a real interest rate cieling at the ZLB.

\footnotetext{
${ }^{6}$ Determination of the price level in this case requires deflation, but the same argument can hold for positive inflation rates if nominal wage growth must be greater than or equal to productivity growth. This assumption shifts up the kink point in the AS curve shown in Figure 1.

${ }^{7}$ This explains the coefficient $\xi^{-1}=\left(Y_{s s}^{m}-D\right) Y_{s s}^{-1}<1$ in front of $\mathbb{E}_{t} \pi_{t+1}$ in Equation (16).
} 


\section{Conclusion}

The overlapping generations model of Eggertsson and Mehrotra (2014) with downward wage rigidities provides a clean analytical framework that rationalizes the low inflation, low growth outcomes observed at the ZLB. It also clearly illustrates the expectational stability issues that arise when monetary policy is no longer active. The role of downward nominal rigidities is shown to play a crucial role in determining the price level at the ZLB, while the overlapping generations assumption is shown to weaken the relationship between output and inflation expectations, which together ensure expectational stability. The results show that asymmetric frictions and overlapping generations may be key to explaining the observed economic stability at the ZLB.

\section{References}

Benhabib, Jess, George W Evans, and Seppo Honkapohja, "Liquidity traps and expectation dynamics: Fiscal stimulus or fiscal austerity?," Journal of Economic Dynamics and Control, 2014, 45, 220-238.

_, Stephanie Schmitt-Grohé, and Martin Uribe, "The perils of Taylor rules," Journal of Economic Theory, 2001, 96 (1), 40-69.

Bullard, James, "Seven faces of "the peril"," Federal Reserve Bank of St. Louis Review, 2010, 92.

Christiano, Lawrence J, Martin Eichenbaum, and Benjamin K Johannsen, "Does the New Keynesian Model Have a Uniqueness Problem?," Working paper, Northwestern University 2016.

Eggertsson, Gauti B and Neil R Mehrotra, "A model of secular stagnation," National Bureau of Economic Research 2014.

Eusepi, Stefano, "Learnability and monetary policy: A global perspective," Journal of Monetary Economics, 2007, 54 (4), 1115-1131.

Evans, George W and Seppo Honkapohja, Learning and expectations in macroeconomics, Princeton University Press, 2001.

_ and _ "Policy interaction, expectations and the liquidity trap," Review of Economic Dynamics, 2005, 8 (2), 303-323. 
_ , Eran Guse, and Seppo Honkapohja, "Liquidity traps, learning and stagnation," European Economic Review, 2008, 52 (8), 1438-1463.

_ , Seppo Honkapohja, and Kaushik Mitra, "Expectations, stagnation and fiscal policy," Working paper, University of Oregon 2016.

Leeper, Eric M and Campbell Leith, "Understanding inflation as a joint monetaryfiscal phenomenon," Technical Report, National Bureau of Economic Research 2016.

Preston, Bruce, "Learning about Monetary Policy Rules when Long-Horizon Expectations Matter," International Journal of Central Banking, 2005.

Schmitt-Grohé, Stephanie and Martın Uribe, "Liquidity Traps and Jobless Recoveries," American Economic Journal: Macroeconomics, 2016.

Summers, Lawrence H, "Secular stagnation, speech at the 14th Annual IMF Research Conference, Washington DC, November 2013; and LH Summers, US economic prospects: secular stagnation, hysteresis, and the zero lower bound," Business Economics, 2014, 49 (2), 65-73. 


\section{Appendix A}

Proposition 1: E-stability is assessed by studying the T-map, which maps agents' beliefs to outcomes (see Evans and Honkapohja (2001)). The T-map is formed by Equation (22) substituting in the PLM (15):

$$
\pi_{t}=\frac{1}{\phi_{\pi}}\left(a+\left(b \rho_{g}+\rho_{g}+\mu\right) d_{t-1}+\left(c \rho_{g}+1\right) g_{t}+(b+1) \epsilon_{d, t}\right)
$$

which implies

$$
T\left(\begin{array}{l}
a \\
b \\
c
\end{array}\right)=\frac{1}{\phi_{\pi}}\left(\begin{array}{c}
a \\
b \rho_{g}+\rho_{g}+\mu \\
c \rho_{g}+1
\end{array}\right)
$$

The E-stability principle states that local stability of the MSV-RE (15) under learning is governed by the stability of the following differential equation in notional time $\tau$

$$
\frac{d \Theta}{d \tau}=T(\Theta)-\Theta=0
$$

where $\Theta=(a, b, c)^{\prime}$. The Jacobian of $d \Theta / d \tau$ is

$$
D T-I=\left(\begin{array}{ccc}
\phi_{\pi}^{-1}-1 & 0 & 0 \\
0 & \phi_{\pi}^{-1} \rho_{d}-1 & 0 \\
0 & 0 & \phi_{\pi}^{-1} \rho_{g}-1
\end{array}\right)
$$

E-stability requires $\phi_{\pi}^{-1}<1$, which holds so long as there is active monetary policy.

Proposition 2: The PLM in this case is given by Equation (18). The T-map is

$$
T\left(\begin{array}{l}
a \\
b \\
c \\
f
\end{array}\right)=\frac{1}{\mu}\left(\begin{array}{c}
a \\
-\mu^{2}+b \rho_{d}+\rho_{d}^{2} \\
-\mu+\rho_{g}+c \rho_{g} \\
b+\rho_{d}
\end{array}\right) .
$$

The Jacobian of $d \Theta / d \tau$ is 


$$
D T-I=\left(\begin{array}{cccc}
\mu^{-1}-1 & 0 & 0 & 0 \\
0 & \mu^{-1} \rho_{d}-1 & 0 & 0 \\
0 & 0 & \mu^{-1} \rho_{g}-1 & 0 \\
0 & \mu^{-1} & 0 & -1
\end{array}\right)
$$

The E-stability conditions are $\mu^{-1}<1, \rho_{d} \mu^{-1}<1$, and $\rho_{g} \mu^{-1}<1$.

Proposition 3: The PLM in this case is given by Equation (15). The T-map is

$$
T\left(\begin{array}{l}
a \\
b \\
c
\end{array}\right)=\left(\begin{array}{c}
m_{0} a \\
m_{0} b \rho_{d}+m_{1} \rho_{d}+m_{2} \\
m_{0} c \rho_{g}+m_{1}
\end{array}\right) .
$$

The Jacobian of $d \Theta / d \tau$ is

$$
D T-I=\left(\begin{array}{ccc}
m_{0}-1 & 0 & 0 \\
0 & m_{0} \rho_{d}-1 & 0 \\
0 & 0 & m_{0} \rho_{g}-1
\end{array}\right) .
$$

The conditions for E-stability are $m_{0}<1, m_{0} \rho_{d}<1$, and $m_{0} \rho_{g}<1$.

In order for the secular stagnation steady state to exist, it must be the case that

$$
\frac{d \Pi}{d Y} A S<\frac{d \Pi}{d Y} A D
$$

in neighborhood of the steady state. This implies that 


$$
\begin{aligned}
& \frac{1-\alpha}{\alpha} \frac{\Pi_{s s}}{\gamma Y_{s s}}\left(\Pi_{s s}-\gamma\right)<\frac{\Pi_{s s}}{Y_{s s}-D} \\
& \frac{1-\alpha}{\alpha} \frac{Y_{s s}-D}{Y_{s s}}\left(\frac{\Pi_{s s}}{\gamma}-1\right)<1 \\
& \frac{1-\alpha}{\alpha} \frac{Y_{s s}-D}{Y_{s s}} \frac{\Pi_{s s}}{\gamma}<\frac{1-\alpha}{\alpha} \frac{Y_{s s}-D}{Y_{s s}}+1 \\
& 1<\frac{\gamma}{\Pi_{s s}}\left(1+\frac{\alpha}{1-\alpha} \frac{Y_{s s}}{Y_{s s}-D}\right) \\
& m_{0}=\left(\frac{\gamma}{\Pi_{s s}}\left(1+\frac{\alpha}{1-\alpha} \frac{Y_{s s}}{Y_{s s}-D}\right)\right)^{-1}<1 \text {. }
\end{aligned}
$$

Therefore, so long as the secular stagnation equilibrium exists, it is E-stable.

\section{Appendix B}

Schmitt-Grohé and Uribe (2016) use the assumption of downwardly rigid nominal wages to construct a liquidity trap equilibrium as in Benhabib et al. (2001) that also features unemployment. This appendix studies the E-stability properties of their unemployment equilibrium.

Schmitt-Grohé and Uribe (2016) consider an economy populated by infinitely lived households that seek to maximize the following utility function

$$
\mathbb{E}_{t} \sum_{t=0}^{\infty} e^{\zeta_{t}} \frac{C_{t}^{1-\sigma}-1}{1-\sigma}
$$

subject to

$$
P_{t} C_{t}+B_{t}=W_{t} h_{t}+R_{t-1} B_{t-1}+\Phi_{t}-T_{t}
$$

where $C_{t}$ is consumption, $B_{t}$ is the stock of risk free nominal bonds, $W_{t}$ is nominal wages, $h_{t} \leq \bar{h}$ is hours of labour supplied, $\Phi_{t}$ is nominal profit from ownership in firms, and $T_{t}$ is nominal lump sum taxes.

The production side of the economy is assumed perfectly competitive. Production is Cobb-Douglas in hours

$$
Y_{t}=X_{t} h_{t}^{\alpha}
$$

where $0<\alpha<1$ and $X_{t}$ is a deterministic productivity process $X_{t}=\mu X_{t-1}$ with $\mu>0$. Wages are paid according to marginal product but subject to a downward rigidity such 
that

$$
\frac{W_{t}}{W_{t-1}} \geq \gamma\left(u_{t}\right)
$$

where $\gamma\left(u_{t}\right)=\gamma_{0}\left(1-u_{t}\right)^{\gamma_{1}}$ and $u_{t}=\left(\bar{h}-h_{t}\right) / \bar{h}$. They also assume a slackness condition that ensures either the wage rigidity condition binds or $h_{t}=\bar{h}$.

The government is assumed to levy lump sum taxes, issues public debt, and balances the budget in every period. Monetary policy follows a Taylor rule

$$
R_{t}=\max \left\{1, R^{*}+\alpha_{\pi}\left(\pi_{t}-\pi^{*}\right)+\alpha_{y} \ln \left(\frac{Y_{t}}{Y_{t}^{*}}\right)\right\} .
$$

Schmitt-Grohé and Uribe show under the following assumptions that a unique unemployment steady state exists $(u=\bar{u}>0)$ that is in a liquidity $\operatorname{trap}(R=1$ and $\left.\pi=\beta \mu^{-\sigma}<\pi^{*}\right)$ :

1. $\gamma_{0}, \gamma_{1}>0$

2. $R^{*}=\pi^{*} \beta^{-1}>1$

3. $\alpha_{\pi} \beta \mu^{-\sigma}>1$

4. $\pi^{*}>\gamma(0) \mu^{-1}$

\section{B.1 E-stability of the Unemployment Steady State}

Following Preston (2005), the log-linear approximation of the individual agent's consumption decision at the unemployment steady state, under subjective expectations $\left(\tilde{\mathbb{E}}_{t}\right)$, may be expressed as

$$
c_{t}=\tilde{\mathbb{E}}_{t} \sum_{T=t}^{\infty} \tilde{\beta}^{T-t}\left[(1-\tilde{\beta}) c_{T+1}+\sigma^{-1} \pi_{T+1}+\psi_{T}\right] \text {, }
$$

where $\tilde{\beta}=\beta \mu^{-\sigma}, \psi_{t}=\sigma^{-1}\left(\zeta_{t}-\zeta_{t+1}\right)$, and where it is assumed that agents' expect monetary policy to remain constrained by the ZLB indefinitely.

The log-linear approximation of the supply side of the economy with the wage constraint binding is

$$
\pi_{t}=\frac{1+\gamma_{1}-\alpha}{\alpha} y_{t}-\frac{1-\alpha}{\alpha} y_{t-1} .
$$

Using Equation (B1), (B3), and $c_{t}=y_{t}$, I substitute out expectations of inflation in Equation (B2) for expectations of output: 


$$
y_{t}=\frac{\alpha \sigma}{1+\alpha(\sigma-1)} \tilde{\mathbb{E}}_{t} \sum_{T=t}^{\infty} \tilde{\beta}^{T-t}\left[\left(1-\tilde{\beta}+\frac{\gamma_{1}}{\alpha \sigma}\right) y_{T+1}+\psi_{T}\right] .
$$

The minimum state variable rational expectations (MSV-RE) solution in this case has the following functional form

$$
y_{t}=a+b \psi_{t}
$$

where $\psi_{t}=\rho \psi_{t-1}+\epsilon_{t}$. I assume agents know the functional form of Equation (B5) and use it to forecast $y_{t}$. Substituting in the forecasts for $y_{t}$, the actual law of motion for the economy is given by

$$
y_{t}=\Gamma_{0} \Gamma_{1} \frac{a}{1-\tilde{\beta}}+\Gamma_{0}\left(\Gamma_{1} \frac{b \rho}{1-\tilde{\beta} \rho}+1\right) \psi_{t}
$$

where

$$
\Gamma_{0}=\frac{\alpha \sigma}{1+\alpha(\sigma-1)} \quad \text { and } \quad \Gamma_{1}=1-\tilde{\beta}+\frac{\gamma_{1}}{\alpha \sigma}
$$

Proposition 4: The unemployment equilibrium is E-stable if the following conditions are satisfied

1. $0<\gamma_{1}<1$

2. $0<\tilde{\beta}<1-\gamma_{1}$

3. $0<\alpha<\frac{\tilde{\beta}+\gamma_{1}-1}{\tilde{\beta}-1}$

or combining the conditions: $\gamma_{1}<1+\alpha(\tilde{\beta}-1)-\tilde{\beta}$.

Proof: The T-map is given by

$$
T=\left(\begin{array}{l}
a \\
b
\end{array}\right)=\left(\begin{array}{c}
\Gamma_{0} \Gamma_{1} \frac{a}{1-\tilde{\beta}} \\
\Gamma_{0}\left(\Gamma_{1} \frac{b \rho}{1-\tilde{\beta} \rho}+1\right)
\end{array}\right)
$$

E-stability requires the real parts of the eigenvalues of DT to be less than one. The eigenvalues in this case are 


$$
\frac{\alpha(\tilde{\beta}-1) \sigma-\gamma_{1}}{(\tilde{\beta}-1)(1+\alpha(\sigma-1))} \text { and } \frac{\rho\left(\alpha(\tilde{\beta}-1) \sigma-\gamma_{1}\right)}{(\tilde{\beta} \rho-1)(1+\alpha(\sigma-1))}
$$

The result follows from manipulating the implied inequalities.

For plausible calibrations of the model, this implies very small values for $\gamma_{1}$ i.e. an extreme rigidity in nominal wages. 